\title{
A FURTHER GENERALIZATION OF THE SOLOW GROWTH MODEL: THE ROLE OF THE PUBLIC SECTOR
}

\author{
Oscar Bajo-Rubio \\ (Universidad Pública de Navarra)
}

\begin{abstract}
We develop in this paper an augmented version of the Solow (1956) growth model, including the role of government. The model leads to a non-monotonic relationship between the rate of growth of per capita output and government size, generalizing previous results by Barro (1990) to the case in which returns to scale to private factors are not constant.
\end{abstract}

Key words: Economic growth; Neoclassical and augmented growth models; Public capital; Transfers; Fiscal policy

JEL Classification: E62; O40 


\section{Introduction}

It has become widely accepted that the Solow (1956) growth model, augmented by the inclusion of other productive factors in addition to private capital and labor, is able to explain roughly well cross-country differences in growth rates of per capita income [see, e. g., Barro and Sala-i-Martin (1995), Mankiw, Romer and Weil (1992), or Nonneman and Vanhoudt (1996)].

A certain amount of this empirical research is addressed to analyze the effects of fiscal policy on growth [which is surveyed, e. g., in Slemrod (1995) or Tanzi and Zee (1997)]. The standard result of this literature is that of Barro (1991), who finds a negative and significant effect of the level of public consumption as a percentage of GDP (which would proxy government size), on the growth rate of a cross section of countries. This is justified on the grounds that a greater government intervention would distort the incentives systems, so that a higher government size would be associated with a lower productivity, and hence a lower growth. However, this effect did not appear robust to changes in the conditioning variables in the influential study of Levine and Renelt (1992). In addition, and more important, it does not seem very clear the use of government consumption as a proxy of the whole public expenditure, since there would be other components more directly linked to growth.

On the other hand, most of the empirical literature on fiscal policy and growth is not based on an explicit theoretical framework, adding only a proxy of the size of the public sector (usually, government consumption), in an ad hoc fashion, to a standard convergence equation. In fact, fiscal policy instruments have been embodied in theoretical models of growth only from the point of view of endogenous growth. So, Barro (1990) considers public services as a productive 
(flow) input, and, by taking into account how the government finances those services, obtains a non-linear relationship between government size and growth. Subsequently, Cashin (1995) modifies Barro's model to include into the production function the government's capital stock (rather than a flow input), as well as the role of transfer payments.

The aim of this paper is to develop an augmented version of the Solow growth model, including the role of government. The model will lead to a growth equation in terms of the shares of private factors and fiscal policy instruments, with a non-monotonic relationship between government size and growth. As a by-product of the analysis, we will be able to derive an expression for the "optimal" government size.

\section{A model of fiscal policy and growth}

The production function of our model will include, together with private inputs, those government inputs that could a priori be thought to strictly affecting the level of output. One is a reproducible factor, entering directly into the production function: public physical capital. The other is assumed to influence indirectly, via externalities, the incentives to accumulation and growth; following Cashin (1995), this input will be called transfer payments. The inclusion of transfers may be justified since they would allow to reinforce property rights (on raising the opportunity cost of criminal activities), as well as retiring from the labor force those people with a lower level of human capital (Sala-i-Martin, 1996,1997).

Hence, we postulate a production function such as: 


$$
Y=K^{\alpha} Z_{1}^{\beta_{1}} \ldots Z_{m}^{\beta_{m}}(A L)^{1-\alpha-\sum_{i=1}^{m} \beta_{i}}\left(\frac{K G}{K}\right)^{\gamma}\left(\frac{T R}{K}\right)^{\theta}
$$

where $Y$ denotes output; $K$ is private physical capital, $Z_{i}(i=1, \ldots, m)$ are other private inputs (such as human capital -as in Mankiw, Romer and Weil (1992)-, knowledge capital -as in Nonneman and Vanhoudt (1996)-, and the like), $L$ is labor, and $A$ is a labor-augmenting factor; finally, $K G$ and $T R$ are the government-provided inputs: public physical capital and transfer payments, respectively.

Notice that our formulation allows for congestion of the public services, which would be rival but non excludable goods: every producer benefits from the provision of public inputs but, for a given level of the latter, the quantity available to each producer declines as other producers raise their levels of private inputs (Barro and Sala-i-Martin, 1992). In the production function above, it is assumed that $\alpha>\gamma+\theta$.

Writing the production function in per capita terms we have:

$$
y=A \bar{k}^{\alpha} \bar{z}_{1}^{\beta_{1}} \ldots \bar{z}_{m}^{\beta_{m}}\left(\frac{K G}{K}\right)^{\gamma}\left(\frac{T R}{K}\right)^{\theta}
$$

where small letters denote per capita variables, and small letters with a bar indicate per capita variables in efficiency units (i. e., for any variable $X: x=X / L, \bar{x}=X / A L$ ). Notice that the per capita production function (2) exhibits decreasing returns to scale in both private capital and all private inputs, for a given state of congestion in the use of public capital and transfers. This differs from Barro (1990), where private capital was subject to constant returns to scale. 
Next, we turn to the accumulation equations. We assume that private reproducible factors accumulate according to the following equations:

$$
\begin{gathered}
\dot{K}=s_{K}(1-\tau) Y-\delta K \\
\dot{Z}_{i}=s_{Z_{i}}(1-\tau) Y-\delta Z_{i} \quad \forall i=1, \ldots, m
\end{gathered}
$$

where $s_{K}$ and $s_{Z_{i}}$ are the shares of gross investment on private physical capital and the other private inputs, respectively, in private output, being $\tau$ the size of the public sector (i. e., the share of the public budget in total output); $\delta$ is the depreciation rate (assumed to be the same for all inputs); and a dot over a variable denotes its time derivative. In a similar way, public capital would accumulate according to:

$$
\dot{K} G=s_{K G} \tau Y-\delta K G
$$

where $s_{K G}$ is now the share of gross public investment in public output, and the depreciation rate is again assumed to be the same than for private inputs.

From here, the rates of change in the stocks of the reproducible factors, in efficiency terms, would be given by:

$$
\begin{gathered}
g_{\bar{k}}=\frac{\dot{K}}{K}-g_{A}-n \\
g_{\bar{z}_{i}}=\frac{\dot{Z}_{i}}{Z_{i}}-g_{A}-n \quad \forall i=1, \ldots, m \\
g_{\overline{k g}}=\frac{\dot{K} G}{K G}-g_{A}-n
\end{gathered}
$$


where $g_{X}$ denotes the rate of growth of variable $X$, and $n$ is the rate of population growth (i. e., $\left.n=g_{L}\right)$; in particular, $g_{A}$ is the rate of technical progress. By equating (6), (7), and (8) to zero, we can find the steady-state values of $\bar{k}, \bar{z}_{i}$, and $\overline{k g}$; and, assuming further that:

$$
\overline{\operatorname{tr}}^{*}=\frac{s_{T R} \tau y^{*}}{A}
$$

where $s_{T R}$ is the share of transfers in public output, and asterisks denote steady-state values, we can obtain the (log of the) steady-state per capita output by replacing those values in the steadystate counterpart of equation (2):

$$
\begin{aligned}
\ln y^{*}= & \ln A_{0}+g_{A} t-\frac{\alpha+\sum_{i} \beta_{i}-\theta}{1-\alpha-\sum_{i} \beta_{i}} \ln \left(\delta+g_{A}+n\right)+\frac{\alpha-\gamma-\theta}{1-\alpha-\sum_{i} \beta_{i}} \ln s_{K}+ \\
& +\frac{\beta_{1}}{1-\alpha-\sum_{i} \beta_{i}} \ln s_{Z_{1}}+\ldots+\frac{\beta_{m}}{1-\alpha-\sum_{i} \beta_{i}} \ln s_{Z_{m}}+\frac{\gamma}{1-\alpha-\sum_{i} \beta_{i}} \ln s_{K G}+ \\
& +\frac{\theta}{1-\alpha-\sum_{i} \beta_{i}} \ln s_{T R}+\frac{\gamma+\theta}{1-\alpha-\sum_{i} \beta_{i}} \ln \tau+\frac{\alpha+\sum_{i} \beta_{i}-\gamma-\theta}{1-\alpha-\sum_{i} \beta_{i}} \ln (1-\tau)
\end{aligned}
$$

where $A_{0}$ is the initial value of the technological parameter $A$, i. e., $A_{t}=A_{0} e^{g_{A} t}$, with $t$ denoting time.

To derive a growth equation, we make an approximation around the steady state [see Mankiw, Romer and Weil (1992) or Barro and Sala-i-Martin (1995)], so that, in efficiency terms, we can write: 


$$
\frac{d \ln \bar{y}}{d t}=-\lambda\left(\ln \bar{y}-\ln \bar{y}^{*}\right)+\theta\left(g_{T R}-g_{A}-n\right) t
$$

where $\lambda=\left(1-\alpha-\sum_{i=1}^{m} \beta_{i}+\theta\right)\left(\delta+g_{A}+n\right)$ is the speed of convergence.

Solving the differential equation given by (11), replacing the determinants of the steady state given by equation (10), dividing by $t$, and rearranging, we obtain the final expression for the rate of growth of per capita output:

$$
\begin{aligned}
g_{y}= & (1-\theta) g_{A}+\frac{\left(1-e^{-\lambda t}\right)}{t}\left\{\ln A_{0}-\frac{\alpha+\sum_{i} \beta_{i}-\theta}{1-\alpha-\sum_{i} \beta_{i}} \ln \left(\delta+g_{A}+n\right)+\right. \\
& +\frac{\alpha-\gamma-\theta}{1-\alpha-\sum_{i} \beta_{i}} \ln s_{K}+\frac{\beta_{1}}{1-\alpha-\sum_{i} \beta_{i}} \ln s_{Z_{1}}+\ldots+\frac{\beta_{m}}{1-\alpha-\sum_{i} \beta_{i}} \ln s_{Z_{m}}+ \\
& +\frac{\gamma}{1-\alpha-\sum_{i} \beta_{i}} \ln s_{K G}+\frac{\theta}{1-\alpha-\sum_{i} \beta_{i}} \ln s_{T R}+\frac{\gamma+\theta}{1-\alpha-\sum_{i} \beta_{i}} \ln \tau+ \\
& \left.+\frac{\alpha+\sum_{i} \beta_{i}-\gamma-\theta}{1-\alpha-\sum_{i} \beta_{i}} \ln (1-\tau)-\ln y_{0}\right\}+\theta\left(g_{T R}-n\right)
\end{aligned}
$$

where $y_{0}$ is the initial per capita output, and $g_{y}=\frac{\left(\ln y_{t}-\ln y_{0}\right)}{t}$.

Notice that, in equation (12), $s_{K}$ and $s_{Z_{i}}(i=1, \ldots, m)$ would denote the shares of gross investment on private inputs in private output, and $s_{K G}$ and $s_{T R}$ the shares of gross public investment and transfers in public output, instead of the shares in total output. This allows us to 
derive explicitly from the model a non-monotonic relationship between the rate of growth of per capita output and the size of the public sector, leading to an inverted U-shaped relationship between the two variables. Higher levels of public inputs would lead directly to a higher growth, but they will leave a smaller quantity of output available for the accumulation of private inputs; and the rate of growth of per capita output, together with its steady-state level, would be maximized for:

$$
\tau=\frac{\gamma+\theta}{\alpha+\sum_{i=1}^{m} \beta_{i}}
$$

Notice, finally, that the non-monotonic relationship found between the rate of growth of per capita output and the size of the public sector, as well as the "optimal" size of the latter given by equation (13), would be equivalent to the results derived in Barro (1990), being a generalization of them to the case in which returns to scale to private factors are not constant.

\section{Conclusions}

We have developed in this paper an augmented version of the Solow growth model, including the role of government. To this end, the production function has been extended to incorporate those public inputs presumed to affect strictly the production process (i. e., public capital and transfer payments). The model led to a non-monotonic relationship between the rate of growth of per capita output and the size of the public sector, together with an expression for the "optimal" government size, generalizing Barro's (1990) previous results to the case in which returns to scale to private factors are not constant. Finally, the model presented in this paper 
could be used as a framework for empirical analysis, since most of the empirical literature on fiscal policy and growth is not based on an explicit theoretical model.

\section{References}

Barro, R. 1990. Government spending in a simple model of endogenous growth. Journal of Political Economy 98, S103-S125.

Barro, R. 1991. Economic growth in a cross section of countries. Quarterly Journal of Economics 106, 407-443.

Barro, R., Sala-i-Martin, X. 1992. Public finance in models of economic growth. Review of Economic Studies 59, 645-661.

Barro, R., Sala-i-Martin, X. 1995. Economic growth. McGraw-Hill, New York.

Cashin, P. 1995. Government spending, taxes, and economic growth. International Monetary Fund Staff Papers 42, 237-269.

Levine, R., Renelt, D. 1992. A sensitivity analysis of cross-country growth regressions. American Economic Review 82, 942-963.

Mankiw, G., Romer, D., Weil, D. 1992. A contribution to the empirics of economic growth. Quarterly Journal of Economics 107, 407-437.

Nonneman, W., Vanhoudt, P. 1996. A further augmentation of the Solow model and the empirics of economic growth for OECD countries. Quarterly Journal of Economics 111, 943-953.

Sala-i-Martin, X. 1996. A positive theory of social security. Journal of Economic Growth 1, 277-304.

Sala-i-Martin, X. 1997. Transfers, social safety nets, and economic growth. International Monetary Fund Staff Papers 44, 81-102. 
Slemrod, J. 1995. What do cross-country studies teach about government involvement, prosperity, and economic growth? Brookings Papers on Economic Activity 2, 373-431.

Solow, R. 1956. A contribution to the theory of economic growth. Quarterly Journal of Economics 70, 65-94.

Tanzi, V., Zee, H. 1997. Fiscal policy and long-run growth. International Monetary Fund Staff Papers 44, 179-209. 